\title{
Analisis Faktor Resiko Stress Akibat Kerja pada Pekerja Sektor Formal dan Sektor Informal di Kota Semarang
}

\author{
Analysis of Stress Risk Factors Due to Work in Formal Sector Workers and \\ Informal Sector in Semarang City
}

M. Riza Setiawan

Staf Pengajar Fakultas Kedokteran Universitas Muhammadiyah Semarang *Penulis Korespondensi. Email: dr.rizasetiawan@gmail.com

Telepon: +62-85741994178

\begin{abstract}
Abstrak
Latar Belakang: Stres kerja adalah kondisi tertekan yang dialami pekerja dalam menyelesaikan pekerjaannya yang berakibat pada penurunan performa, efisiensi dan produktivitas bekerja (1). Badan Pusat Statistik pada tahun 2014 menyatakan bahwa 11,6-17,4\% dari 150 juta populasi orang dewasa di Indonesia mengalami gangguan mental emosional atau gangguan kesehatan jiwa berupa stres kerja (2). Faktor penyebab stres akibat kerja diantaranya usia, masa kerja, beban kerja, hubungan interpersonal, peran individu dan pengembangan karir (3).

Metode: Penelitian ini merupakan observasi analitik dengan pendekatan cross sectional dengan mengunakan kuisioner NASA-TLX untuk mengukur tingkat beban kerja mental (4), kuisioner untuk mengukur hubungan interpersonal (5), Kuisioner untuk mengukur peran individu, pengembangan karir dan Kuisioner Life Event Scale untuk mengukur tingkat stres kerja. Sampel pada penelitian ini adalah 30 pekerja sektor formal dan 30 pekerja sektor informal yang memenuhi kriteria insklusi dan eksklusi. Analisis data di lakukan dengan menggunakan analisis bivariat Uji Chi Square untuk membandingkan faktor resiko stres akibat kerja antara pekerja sektor formal dan informal.

Hasil: Uji chi square memperlihatkan masa kerja $(\mathrm{p}=0,008)$, peran individu $(\mathrm{p}=0,017)$ dan pengembangan karier $(\mathrm{p}=$ $0,021)$ merupakan faktor resiko yang berpengaruh terhadap kejadian stress akibat kerja pada pekerja sektor formal (PNS). Usia $(\mathrm{p}=0,029)$, masa kerja $(\mathrm{p}=0,001)$, beban kerja $(\mathrm{p}=0,000)$, hubungan inperpersonal $(\mathrm{p}=0,006)$, peran individu $(\mathrm{p}=0,025)$ dan pengembangan karier $(\mathrm{p}=0,004)$ merupakan faktor resiko yang berpengaruh terhadap kejadian stress akibat kerja pada pekerja sektor informal (buruh pabrik) di Kota Semarang.

Kesimpulan: Ada perbedaan faktor risiko stres akibat kerja pada pekerja sektor formal dan sektor informal di Kota Semarang. Masa kerja, peran individu dan pengembangan karier merupakan faktor resiko yang berpengaruh terhadap kejadian stress akibat kerja pada pekerja sektor formal di Kota Semarang. Usia, masa kerja, beban kerja, hubungan inperpersonal, peran individu dan pengembangan karier merupakan faktor resiko yang berpengaruh terhadap kejadian stress akibat kerja pada pekerja sektor informal.
\end{abstract}

Kata Kunci: stress kerja, pekerja formal, pekerja informal.

\begin{abstract}
Background: Job stress is a stressed condition experienced by workers in completing their work which results in a decrease in performance, efficiency and productivity of work (1). The Central Bureau of Statistics in 2014 stated that 11.6-17.4\% of the 150 million adult population in Indonesia experience mental emotional disorders or mental health disorders in the form of work stress (2). Occupational stress factors include age, years of service, workload, interpersonal relationships, individual roles and career development (3).

Method: This research is analytic observation with cross sectional approach using NASA-TLX questionnaire to measure the level of mental workload (4), questionnaires to measure interpersonal relationships (5), Questionnaires to measure individual roles, career development and Life Event Scale Questionnaire to measure levels work stress. The sample in this study were 30 formal sector workers and 30 informal sector workers who met the inclusion and exclusion criteria. Data analysis was performed using bivariate analysis Chi Square Test to compare risk factors due to work stress between formal and informal sector workers.

Result: The chi square test shows the length of work $(p=0.008)$, the role of individuals $(p=0.017)$ and career development $(p=0.021)$ are risk factors that influence the incidence of work-related stress in formal sector workers (PNS). Age $(p=0.029)$, work period $(p=0.001)$, workload $(p=0,000)$, inperpersonal relationship $(p=0.006)$, individual role $(p=0.025)$ and career development $(p=0.004)$ are risk factors that affect the incidence of work-related stress in informal sector workers (factory workers) in the city of Semarang.

Conclusion: There are differences in risk factors for stress due to work in formal sector workers and the informal sector in Semarang City. Work period, individual role and career development are risk factors that influence the incidence of work-related stress in formal sector workers in Semarang City. Age, years of service, workload,
\end{abstract}


inperpersonal relationships, individual roles and career development are risk factors that influence the incidence of work-related stress in informal sector workers.

Keywords: job stress, formal workers, informal workers.

\section{PENDAHULUAN}

Stres akibat kerja merupakan permasalahan yang diakui diseluruh dunia dan berpengaruh terhadap organisasinya. Pekerja yang stress akan mengalami penurunan kesehatan, penurunan motivasi kerja dan mengakibatkan produktivitas kerja yang menurun. ${ }^{6} \quad$ Stres merupakan kondisi ketegangan yang berpengaruh terhadap emosi, jalan pikiran dan kondisi fisik seseorang akibat individu yang tidak mampu menyesuaikan diri dengan lingkungan. ${ }^{7}$ Sedangkan stres kerja adalah tanggapan atau proses internal atau eksternal yang mencapai tingkat ketegangan fisik dan psikologis sampai pada batas atau melebihi batas kemampuan pegawai. ${ }^{8}$ Selain itu, stres kerja dapat diartikan sebagai suatu keadaan dimana seseorang menghadapi tugas atau pekerjaan yang tidak bisa atau belum bisa dijangkau oleh kemampuannya. ${ }^{9}$ Faktor penyebab stres akibat kerja diantaranya berasal dari dalam diri sendiri atau individual stressor yang berupa usia, jenis kelamin, status gizi, masa kerja, kondisi kesehatan, peran ganda, tipe kepribadian, dan peristiwa atau pengalaman pribadi serta dari group stressor atau stres kerja karena situasi atau keadaan dalam pekerjaan itu sendiri yang berupa beban kerja berlebihan, pengembangan karir serta hubungan yang tidak baik antar rekan kerja, atasan dan bawahan serta stressor keorganisasian. ${ }^{3}$

Laporan National Institue of Occupational Health and Safety (NIOSH) menunjukan bahwa terdapat dua penelitian mengenai tingkat stres kerja ditempat kerja di Amerika, yang pertama hasil survei yang telah dilakukan oleh Familier and Work Institue menunjukan sejumlah $26 \%$ pekerja sering mengalami stres ditempat kerja, yang kedua hasil survei yang telah dilakukan oleh Yale University menunjukan sebanyak 20\% pekerja mengalami stres kerja. ${ }^{10}$ Indonesia dengan jumlah pekerja mencapai 120,4 juta orang di bulan februari 2012 menunjukan timbulnya dampak buruk yang cukup besar akibat dari kejadian stres akibat kerja tersebut. ${ }^{11}$

Di Indonesia, sektor formal merupakan pekerjaan dengan jumlah tenaga kerja yang masih cukup banyak. Gaji tetap tiap bulan merupakan salah satu alasan mengapa pekerjaan sektor formal ini masih sangat diminati. ${ }^{12}$ Yang termasuk kriteria pekerja formal adalah tenaga profesional, teknisi dan sejenisnya, tenaga kepemimpinan dan ketatalaksanaan, tenaga tata usaha dan sejenisnya, tenaga usaha penjualan, tenaga usaha jasa. ${ }^{12}$

Seiring dengan berkembangnya perekonomian di Indonesia, terjadi fenomena peningkatan jumlah penduduk yang bekerja disektor informal. Hal ini didorong oleh tingkat urbanisasi yang tinggi dimana penawaran pasar tenaga kerja mampu direspon oleh permintaan tenaga kerja sektor informal. ${ }^{13}$ Contoh dari jenis kegiatan sektor informal di Kota Semarang antara lain nelayan, buruh industri, buruh bangunan, dan sopir angkutan. Pekerja pada sektor formal maupun sektor informal berpotensi mengalami stres akibat kerja yang diakibatkan berbagai penyebab yang berbeda-beda.

Berdasarkan uraian di atas, dapat dirumuskan masalah penelitian adalah apakah terdapat perbedaan faktor resiko stres akibat kerja antara pekerja sektor formal dan pekerja sektor informal.

\section{METODOLOGI PENELITIAN}

Penelitian ini merupakan penelitian observasi analitik dengan pendekatan cross sectional dengan mengunakan kuisioner NASA-TLX untuk mengukur tingkat beban kerja mental, ${ }^{4}$ kuisioner untuk mengukur 
hubungan interpersonal, ${ }^{5}$ Kuisioner untuk mengukur peran individu, kuesioner untuk mengukut pengembangan karir dan Kuisioner Life Event Scale untuk mengukur tingkat stres kerja. Populasi penelitian adalah seluruh pekerja sektor formal dan sektor informal di Kota Semarang sebanyak 95.457 pekerja untuk pekerja sektor formal meliputi : PNS, TNI dan POLRI dan 261.341 untuk pekerja sektor informal meliputi buruh industri dan buruh bangunan. Dengan menggunakan rumus slovin didapatkan jumlah sampel minimal adalah 30 untuk masing-masing sektor. Sampel penelitian adalah bagian dari populasi yang memenuhi kriteria insklusi dan eksklusi dan di ambil dengan metode cluster random sampling. Analisis data di lakukan dengan menggunakan analisis bivariat Uji Chi Square untuk membandingkan faktor resiko stres akibat kerja antara pekerja sektor formal dan informal

\section{HASIL}

Penelitian telah dilakukan pada bulan Mei - Juli tahun 2018 pada pekerja sektor formal dan sektor informal di Kota Semarang. Data yang diperoleh meliputi usia, masa kerja, beban kerja mental, hubungan interpersonal, peran individu, pengembangan karir dan kejadian stres kerja.

\section{Analisis Bivariat}

Pada analisis bivariat ini bertujuan untuk mengetahui hubungan antar variabel yang diteliti. Tabel 1 menunjukkan tidak ada hubungan yang bermakna antara usia dengan kejadian stres akibat kerja pada pekerja sektor formal $(\mathrm{p}=0,063)$ sedangkan ada hubungan yang bermakna pada pekerja sektor informal $(\mathrm{p}=0,029)$ di Kota Semarang. Tabel 2 menunjukkan ada hubungan yang bermakna antara usia dengan kejadian stres akibat kerja pada pekerja sektor formal $(\mathrm{p}=0,008)$ dan sektor informal $(\mathrm{p}=0,001)$ di Kota Semarang. Tabel 3 menunjukkan tidak ada hubungan yang bermakna antara beban kerja dengan kejadian stres akibat kerja pada pekerja sektor formal $(\mathrm{p}=0,687)$, sedangkan ada hubungan yang bermakna pada pekerja sektor informal $(\mathrm{p}=0,000)$ di Kota Semarang. Tabel 4 menunjukkan tidak ada hubungan yang bermakna antara beban kerja dengan kejadian stres akibat kerja pada pekerja sektor formal $(\mathrm{p}=0,565)$ sedangkan ada hubungan yang bermakna pada pekerja sektor informal $(\mathrm{p}=0,006)$ di Kota Semarang. Tabel 5 menunjukkan hubungan yang bermakna antara beban kerja dengan kejadian stres akibat kerja pada pekerja sektor formal $(\mathrm{p}=0,017)$ dan sektor informal $(\mathrm{p}=0,025)$ di Kota Semarang. Tabel 6 menunjukkan hubungan yang bermakna antara pengembangan karir dengan kejadian stres akibat kerja pada pekerja sektor formal $(\mathrm{p}=0,021)$ dan sektor informal $(\mathrm{p}=0,004) \mathrm{di}$ Kota Semarang.

\section{PEMBAHASAN}

Dari hasil penelitian yang telah dilakukan dan hasil analisa menggunakan SPSS 23 dengan uji Chi Square untuk menemukan hubungan antara faktor resiko (usia, masa kerja, beban kerja, hubungan interpersonal, peran individu dan pengembangan karir) dan stress akibat kerja pada pekerja sektor formal dan sektor informal di kota Semarang, ditemukan bahwa terdapat perbedaan faktor resiko yang berhubungan dengan stress akibat kerja pada pekerja sektor formal dan sektor informal.

\section{a. Faktor risiko stres akibat kerja pada pekerja sektor formal}

Dari hasil penelitian yang telah dilakukan, ditemukan bahwa masa kerja, peran individu dan pengembangan karier merupakan faktor resiko yang berpengaruh terhadap kejadian stress akibat kerja pada pekerja sektor formal (PNS) dengan nilai probabilitas < 0,05 dan berdasarkan uji chi square dan tabel. Dapat di ambil kesimpulan bahwa ada hubungan bermakna antara masa kerja, peran individu dan pengembangan karier dengan kejadian stress akibat kerja pada pekerja sektor formal khususnya pegawai negeri sipil di kota semarang. 
Hal ini sesuai dengan penelitian yang dilakukan oleh Budiono yaitu terdapat hubungan antara masa kerja dengan kejadian stres akibat kerja. Masa kerja adalah lamanya seseorang bekerja ditempat kerja atau merupakan akumulasi aktivitas kerja seseorang yang dilakukan dalam jangka waktu yang panjang. Apabila aktivitas tersebut dilakukan terus menerus dalam jangka waktu bertahun-tahun tentunya dapat menimbulkan kejenuhan pada diri seorang pekerja yang berakibat pada timbulnya stres kerja, umumnya kejenuhan ini timbul pada pekerja yang sudah memiliki masa kerja lebih dari 5 tahun. ${ }^{14}$

Table 1.Hubungan antara usia dengan kejadian stres akibat kerja pada pekerja sektor formal dan informal

\begin{tabular}{|c|c|c|c|c|c|c|}
\hline & Jenis Pekerjaan & Value' & Df & $\begin{array}{c}\text { Asymptotic } \\
\text { Significance } \\
\text { (2-sided) }\end{array}$ & $\begin{array}{l}\text { Exact } \\
\text { Sig. } \\
(2- \\
\text { sided })\end{array}$ & $\begin{array}{c}\text { Exact } \\
\text { Sig. } \\
(1- \\
\text { sided })\end{array}$ \\
\hline Formal & Pearson Chi-Square & $8.906 b$ & 4 & .063 & & \\
\hline & Likelihood Ratio & 8.118 & 4 & .087 & & \\
\hline & Linear-by-Linear Association & 4.212 & 1 & .040 & & \\
\hline & $\mathrm{N}$ of Valid Cases & 30 & & & & \\
\hline Informal & Pearson Chi-Square & $4.739 \mathrm{c}$ & 1 & .029 & & \\
\hline & Continuity Correctiond & 3.230 & 1 & .072 & & \\
\hline & Likelihood Ratio & 4.866 & 1 & .027 & & \\
\hline & Fisher's Exact Test & & & & .057 & .035 \\
\hline & Linear-by-Linear Association & 4.581 & 1 & .032 & & \\
\hline & $\mathrm{N}$ of Valid Cases & 30 & & & & \\
\hline Total & Pearson Chi-Square & $17.905 \mathrm{a}$ & 4 & .001 & & \\
\hline & Likelihood Ratio & 20.458 & 4 & .000 & & \\
\hline & Linear-by-Linear Association & 15.821 & 1 & .000 & & \\
\hline & $\mathrm{N}$ of Valid Cases & 60 & & & & \\
\hline
\end{tabular}

Hal ini juga sesuai dengan teori dari Cooper tentang stress dalam pekerjaan, bahwa peran individu yang berbeda beda dan pengembangan karir yang tidak jelas merupakan salah satu faktor risiko terjadinya stress pada pekerja. Peran Individu yang berbeda bisa berupa peran sebagai pekerja, peran keluarga, peran social dan lain sebagainya. ${ }^{15}$

\section{b. Faktor risiko stress akibat kerja pada pekerja sektor informal}

Dari hasil penelitian yang telah dilakukan, ditemukan bahwa usia, masa kerja, beban kerja, hubungan inperpersonal, peran individu dan pengembangan karier merupakan faktor resiko yang berpengaruh terhadap kejadian stress akibat kerja pada pekerja sektor informal (buruh pabrik) dengan nilai probabilitas $<0,05$ dan berdasarkan uji chi square dan tabel. Dapat di ambil kesimpulan bahwa ada hubungan bermakna antara usia, masa kerja, beban kerja, hubungan inperpersonal, peran individu dan pengembangan karier dengan kejadian stress akibat kerja pada pekerja sektor informal khususnya buruh pabrik di kota semarang.

Hal ini sesuai dengan penelitian yang dilakukan oleh Nur Aini yaitu terdapat hubungan antara usia, masa kerja, beban kerja dengan kejadian stres akibat kerja. Umur dapat mempengaruhi tingkat stress yang dialami seseorang. Pekerja pada usia yang lebih tua cenderung mengalami stress lebih rendah dibandingkan dengan pekerja berumur muda. 
Table 2. Hubungan antara masa kerja dengan kejadian stres akibat kerja pada pekerja sektor formal dan informal

\begin{tabular}{llrrr}
\hline \multicolumn{1}{c}{ Jenis Pekerjaan } & Value & Df & $\begin{array}{r}\text { Asymptotic } \\
\text { Significance } \\
\text { (2-sided) }\end{array}$ \\
\hline Formal & Pearson Chi-Square & $13.929 \mathrm{~b}$ & 4 & .008 \\
& Likelihood Ratio & 9.151 & 4 & .057 \\
& Linear-by-Linear Association & 8.246 & 1 & .004 \\
& N of Valid Cases & 30 & & \\
\hline informal & Pearson Chi-Square & $14.362 \mathrm{c}$ & 2 & .001 \\
& Likelihood Ratio & 17.498 & 2 & .000 \\
& Linear-by-Linear Association & 13.051 & 1 & .000 \\
& N of Valid Cases & 30 & & \\
\hline Total & Pearson Chi-Square & $29.887 \mathrm{a}$ & 4 & .000 \\
& Likelihood Ratio & 31.518 & 4 & .000 \\
& Linear-by-Linear Association & 26.733 & 1 & .000 \\
N of Valid Cases & 60 & & \\
\hline
\end{tabular}

Table 3. . Hubungan antara beban kerja dengan kejadian stres akibat kerja pada pekerja sektor formal dan informal

\begin{tabular}{llrrr}
\hline \multicolumn{1}{c}{ Jenis Pekerjaan } & Value & Df & $\begin{array}{c}\text { Asymptotic } \\
\text { Significance } \\
\text { (2-sided) }\end{array}$ \\
\hline Formal & Pearson Chi-Square & $2.266 \mathrm{~b}$ & 4 & .687 \\
& Likelihood Ratio & 3.349 & 4 & .501 \\
& Linear-by-Linear Association & .005 & 1 & .943 \\
& N of Valid Cases & 30 & & .000 \\
\hline \multirow{2}{*}{ informal } & Pearson Chi-Square & $19.094 \mathrm{c}$ & 2 & .000 \\
& Likelihood Ratio & 24.427 & 2 & .000 \\
& Linear-by-Linear Association & 18.389 & 1 & .000 \\
& N of Valid Cases & 30 & & .000 \\
\hline Total & Pearson Chi-Square & $20.958 \mathrm{a}$ & 4 & .000 \\
& Likelihood Ratio & 20.917 & 4 & \\
& Linear-by-Linear Association & 15.495 & 1 & \\
& N of Valid Cases & 60 & & \\
\hline
\end{tabular}

Table 4. Hubungan antara hubungan interpersonal dengan kejadian stres akibat kerja pada pekerja sektor formal dan informal

\begin{tabular}{llrrr}
\hline \multicolumn{1}{c}{ Jenis Pekerjaan } & Value` & Df & $\begin{array}{c}\text { Asymptotic } \\
\text { Significance } \\
\text { (2-sided) }\end{array}$ \\
\hline Formal & Pearson Chi-Square & $4.833 \mathrm{~b}$ & 6 & .565 \\
& Likelihood Ratio & 6.263 & 6 & .394 \\
& Linear-by-Linear Association & .111 & 1 & .739 \\
& N of Valid Cases & 30 & & \\
\hline informal & Pearson Chi-Square & $12.304 \mathrm{c}$ & 3 & .006 \\
& Likelihood Ratio & 14.830 & 3 & .002 \\
& Linear-by-Linear Association & 10.875 & 1 & .001 \\
& N of Valid Cases & 30 & & .012 \\
\hline Total & Pearson Chi-Square & $16.331 \mathrm{a}$ & 6 & .004 \\
& Likelihood Ratio & 18.904 & 6 & .043 \\
& Linear-by-Linear Association & 4.105 & 1 & \\
\hline N of Valid Cases & 60 & & \\
\hline
\end{tabular}


Table 5. . Hubungan antara peran individu dengan kejadian stres akibat kerja pada pekerja sektor formal dan informal

\begin{tabular}{|c|c|c|c|c|c|c|}
\hline & Jenis Pekerjaan & Value' & Df & $\begin{array}{c}\text { Asymptotic } \\
\text { Significance } \\
(2 \text {-sided })\end{array}$ & $\begin{array}{l}\text { Exact Sig. } \\
\text { (2-sided }\end{array}$ & $\begin{array}{c}\text { Exact Sig. } \\
\text { (1-sided }\end{array}$ \\
\hline \multirow[t]{4}{*}{ Formal } & Pearson Chi-Square & $5.000 \mathrm{~b}$ & 4 & .017 & & \\
\hline & Likelihood Ratio & 5.371 & 4 & .251 & & \\
\hline & Linear-by-Linear Association & 2.542 & 1 & .111 & & \\
\hline & $\mathrm{N}$ of Valid Cases & 30 & & & & \\
\hline \multirow[t]{6}{*}{ Informal } & Pearson Chi-Square & $5.000 \mathrm{c}$ & 1 & .025 & \multirow{6}{*}{.046} & \multirow{6}{*}{.032} \\
\hline & Continuity Correctiond & 3.374 & 1 & .066 & & \\
\hline & Likelihood Ratio & 5.187 & 1 & .023 & & \\
\hline & Fisher's Exact Test & & & & & \\
\hline & Linear-by-Linear Association & 4.833 & 1 & .028 & & \\
\hline & $\mathrm{N}$ of Valid Cases & 30 & & & & \\
\hline \multirow[t]{4}{*}{ Total } & Pearson Chi-Square & $4.722 \mathrm{a}$ & 4 & .317 & & \\
\hline & Likelihood Ratio & 5.128 & 4 & .274 & & \\
\hline & Linear-by-Linear Association & 3.252 & 1 & .071 & & \\
\hline & $\mathrm{N}$ of Valid Cases & 60 & & & & \\
\hline
\end{tabular}

Table 6. Hubungan antara pengembangan karir dengan kejadian stres akibat kerja pada pekerja sektor formal dan informal

\begin{tabular}{llrrr}
\hline \multicolumn{1}{c}{ Jenis Pekerjaan } & Value & Df & $\begin{array}{c}\text { Asymptotic } \\
\text { Significance } \\
\text { (2-sided) }\end{array}$ \\
\hline Formal & & $14.931 \mathrm{~b}$ & 6 & .021 \\
& Pearson Chi-Square & 14.345 & 6 & .026 \\
& Likelihood Ratio & 2.506 & 1 & .113 \\
& Linear-by-Linear Association & 30 & & .004 \\
& N of Valid Cases & $11.051 \mathrm{c}$ & 2 & .003 \\
\hline Informal & Pearson Chi-Square & 11.926 & 2 & .002 \\
& Likelihood Ratio & 10.075 & 1 & \\
& Linear-by-Linear Association & 30 & & .108 \\
& N of Valid Cases & & & .181 \\
& & $10.425 \mathrm{a}$ & 6 & .251 \\
\hline Total & Pearson Chi-Square & 8.879 & 6 & \\
& Likelihood Ratio & 1.315 & 1 & \\
& Linear-by-Linear Association & 60 & & \\
N of Valid Cases & & & \\
\hline
\end{tabular}


Pengalaman stress pada pekerja yang berumur tua lebih banyak dibandingkan dengan pekerja muda. Pengaruh umur terhadap stress yang dialami pekerja biasanya hanya terjadi pada pekerjaan tertentu terutama yang berhubungan dengan kekuatan fisik dan penggunaan indera. Masa kerja berhubungan dengan pengalaman pekerja dalam menghadapi permasalahan di tempat kerja.

Pekerja yang memiliki masa kerja lebih lama biasanya memiliki permasalahan kerja yang lebih banyak dibandingkan dengan pekerja dengan masa kerja yang masih sedikit. Masa kerja yang berhubungan dengan stress kerja berkaitan dalam menimbulkan kejenuhan dalam bekerja. Pekerja yang telah bekerja lebih dari lima tahun biasanya memiliki tingkat kejenuhan kerja yang lebih tinggi dibandingkan dengan pekerja baru. Kejenuhan ini yang kemudian dapat berdampak pada timbulnya stress ditempat kerja. Beban kerja baik mental maupun fisik berpotensi menjadi sumber stres di tempat kerja. Bekerja di bawah tekanan waktu untuk mencapai target merupakan sumber stres yang seringkali terdapat di tempat kerja. Hasil penelitian ditemukan bahwa tingkat stress akan meningkat seiring dengan semakin dekatnya target yang ditentukan. Pekerja di Jepang menunjukkan bahwa jumlah beban kerja secara signifikan berkaitan dengan munculnya sejumlah gejala stress, seperti mudah marah, kelelahan, gelisah, dan gejala depresi. ${ }^{16}$

\section{Kesimpulan}

Berdasarkan hasil penelitian tentang analisis faktor risiko stres akibat kerja pada pekerja sektor formal dan sektor informal di Kota Semarang, yang telah dilakukan maka diambil kesimpulan bahwa:

1. Ada perbedaan faktor risiko stres akibat kerja pada pekerja sektor formal dan sektor informal di Kota Semarang.

2. Masa kerja, peran individu dan pengembangan karier merupakan faktor
Juni 2019

resiko yang berpengaruh terhadap kejadian stress akibat kerja pada pekerja sektor formal (PNS) di Kota Semarang.

3. Usia, masa kerja, beban kerja, hubungan inperpersonal, peran individu dan pengembangan karier merupakan faktor resiko yang berpengaruh terhadap kejadian stress akibat kerja pada pekerja sektor informal (buruh pabrik) di kota Semarang.

Saran bagi penelitian berikutnya adalah melakukan penelitian terhadap stress akibat kerja pada pekerja sector formal dan informal dengan variasi jenis pekerjaan yang lebih banyak dengan menggunakan desain penelitian kasus kontrol.

\section{Daftar Pustaka}

1. Tarwaka. Ergonomi Industri. Surakarta: Harapan Press, 2011. 135

2. Data Badan Pusat Statistika (BPS). Tentang populasi orang dewasa di Indonesia yang mengalami stres akibat kerja; 2014

3. Fitri AM. Analisis faktor-faktor yang berhubungan dengan kejadian stres kerja pada karyawan Bank (studi pada karyawan Bank BMT). Semarang : Universitas Diponegoro. 2013.

4. Rauf F. Analisis Beban Mental Menggunakan Metode National Aeronautics And Space AdministrationTask Load Index (Nasa-Tlx) Di PPPPTK Bmti Di Departemen Mesin Bandung. Tugas Akhir Universitas Komputer Indonesia; 2012.

5. Aulya D. Faktor-faktor yang Berhubungan dengan Stres Kerja pada Polisi Lalu Lintas di POLRES METRO Jakarta Pusat Bulan April Agustus Tahun 2013. Jakarta : Universitas Islam Negeri Syarif Hidayatullah. 2013.

6. World Health Organization. Work organisation and Stress. Prot Work Heal. 2003;(3):1-27. 
7. Rose VE, Richard ML. Occupational health hazards in hospitals. Prof Saf. 1980;24(12):11-4.

8. Cooper RK, Ayman S. Executive EQ. Kecerdasan Emosional dalam Kepemimpinan dan Organisasi. Jakarta: PT Gramedia Pustaka Utama; 1998.

9. Health W, Queensland S. Overview of work-related stress. 2011.

10. NIOSH publication: 99: 101, 2002, [Accesed 28th Juli 2009]. Available from World Wide Wb: http://www.cdc.gov/niosh/stresswk.ht $\underline{\mathrm{ml}}$

11. Badan Pusat Statistik. Keadaan Ketenagakerjaan Februari 2012. Berita Resmi Statistik No. 33/05/Th. XV, 7 Mei 2012. (www.bps.go.id/brs_file/naker_07mei 12.pdf diakses tanggal 21 Mei 2012)

12. Meng $X$. The Informal Sector and Rural-Urban Migration - A Chinese Case Study. Asian Economic Journal. 2001, Vol 15 No. 1. 2001.

13. Hasbi Ibrahim, Munawir Amansyah, dan Githa Nurfarida Yahya. Faktorfaktor Yang Berhubungan Dengan Sters Kerja Pada Pekerja Factory 2 PT. Maruki Internasional Indonesia Makassar. FKIK UIN Alauddin Makassar. 2016.

14. Budiono, Sugeng. Bunga Rampai Higiene Perusahaan Ergonomi (HIPERKES) dan Kesehatan serta Keselamatan Kerja. Semarang : Universitas Diponegoro. 2003.
15. Cooper CL, Dewe P J, O'Driscoll MP. Organizaional stress: A review and critique of theory, research and application. Thousand Oaks: Sage Publication; 2001.

16. Nur Aini. Factor risiko stress akibat kerja pada pekerja sector informal di Semarang, 2018 